\title{
Optimization of Vertical Well Placement for Oil Field Development Based on Basic Reservoir Rock Properties using Genetic Algorithm
}

\author{
Tutuka Ariadji ${ }^{1}$, Pudjo Sukarno ${ }^{1}$, Kuntjoro Adji Sidarto ${ }^{2}$, Edy Soewono $^{2}$, \\ Lala Septem $\operatorname{Riza}^{2} \&$ Kenny David ${ }^{1}$ \\ ${ }^{1}$ Department of Petroleum Engineering, Institut Teknologi Bandung, \\ Bandung 40132, Indonesia \\ ${ }^{2}$ Department of Mathematics, Institut Teknologi Bandung, Bandung 40132, Indonesia \\ Email: tutukaariadji@tm.itb.ac.id
}

\begin{abstract}
Comparing the quality of basic reservoir rock properties is a common practice to locate new infills or development wells for optimizing an oil field development using a reservoir simulation. The conventional technique employs a manual trial and error process to find new well locations, which proves to be time-consuming, especially, for a large field. Concerning this practical matter, an alternative in the form of a robust technique was introduced in order that time and efforts could be reduced in finding best new well locations capable of producing the highest oil recovery.

The objective of the research was to apply Genetic Algorithm (GA) in determining wells locations using reservoir simulation to avoid the manual conventional trial and error method. GA involved the basic rock properties, i.e., porosity, permeability, and oil saturation, of each grid block obtained from a reservoir simulation model, which was applied into a newly generated fitness function formulated through translating the common engineering practice in the reservoir simulation into a mathematical equation and then into a computer program. The maximum of the fitness value indicated a final searching of the best grid location for a new well location. In order to evaluate the performance of the generated GA program, two fields that had different production profile characteristics, namely the $\mathrm{X}$ and $\mathrm{Y}$ fields, were applied to validate the proposed method. The proposed GA method proved to be a robust and accurate method to find the best new well locations for field development. The key success of this proposed GA method is in the formulation of the objective function.
\end{abstract}

Keywords: fitness function; field development; Genetic Algorithm; objective function; reservoir simulation; well locations, optimization, vertical well placement.

\section{$1 \quad$ Introduction}

Development of an oil field requires a reservoir model to find the best development scenario of locating new infill wells to maximize oil recovery. The conventional technique, which is conducted manually, to determine well locations uses a trial and error process, honoring the remaining oil saturation

Received April $28^{\text {th }}, 2011$, Revised August $1^{\text {st }}, 2011,2^{\text {nd }}$ Revision November $14^{\text {th }}, 2011$, Accepted for publication June $21^{\text {st }}, 2012$.

Copyright $@ 2012$ Published by LPPM ITB \& PII, ISSN: 1978-3051, DOI: 10.5614/itbj.eng.sci.2012.44.2.2 
and reservoir rock characteristics. Obviously this process is time consuming and cannot guarantee the best results, especially, for a large size field or for a compositional reservoir simulation model, such as a condensate gas field. Therefore, it is essential to find a newly different approach to determine well locations that is much faster and sufficiently accurate.

Genetic Algorithm (GA) is a common method in mathematics research [1-3] for solving a complex optimization problems, and it has been applied in petroleum engineering for reservoir development [4] and well placement optimization [56], reservoir characterization [7-8], and geophysics [9] studies during the year 1997 until 2004. This method is basically a random search method based on the mechanism of natural evolution to determine an optimum solution of a complex problem. The process involves selection, crossover, and mutation of a gene that, in this case, is a product of objective functions [1-3]. Thus, a GA application needs objective functions in order to solve optimization problems; the more appropriate the objective functions are, the more accurate the result is.

The objective of this research was to implement the GA method in order to avoid the conventional trial and error process during reservoir simulation in determining optimum well placement of infill wells to maximize an oil field recovery. The very important first step was an investigation of selected objective functions. This step was conducted by translating the common reservoir simulation practice in petroleum engineering that is the trial and error selection technique for best well locations anticipated to be having best oil production in the future using basic reservoir properties maps. This procedure is represented as an algorithm coded in a computer program. After several logical attempts using the chosen basic reservoir properties formulation, an objective function was introduced for a generated GA to be coded in a computer programming. Thus, a computer program was developed employing three basic reservoir properties, which were oil saturation, porosity, and permeability, as the objective functions and for executing the algorithm calculation process involving the selection for the best solution among numbers in a population.

This research validates the production performance of well placement obtained from the generated genetic algorithm method by applying the predicted well locations into the reservoir simulator of two reservoir models, namely $\mathrm{X}$ and $\mathrm{Y}$ fields. The result of the validation of the generated GA application for field development scenario using reservoir simulation model proves that this method is robust and sufficiently accurate. The benefit of using this method is that there is no need to run a reservoir simulator in order to find the best well location by assuming various well location scenarios that are usually conducted during the reservoir simulation. Therefore, this new approach will reduce the computation time, working hours, and of course, cost. 


\section{Research Methodology}

This study attempts to apply the GA method to replace the conventional time consuming-trial and error technique in the reservoir simulation with the proposed GA method as depicted by the following flow chart of methodology (Figure 1). The reservoir model developed through combining the available geological model and a set of reservoir data was employed as an input to the proposed GA method in a well location optimization for maximizing oil field recovery.

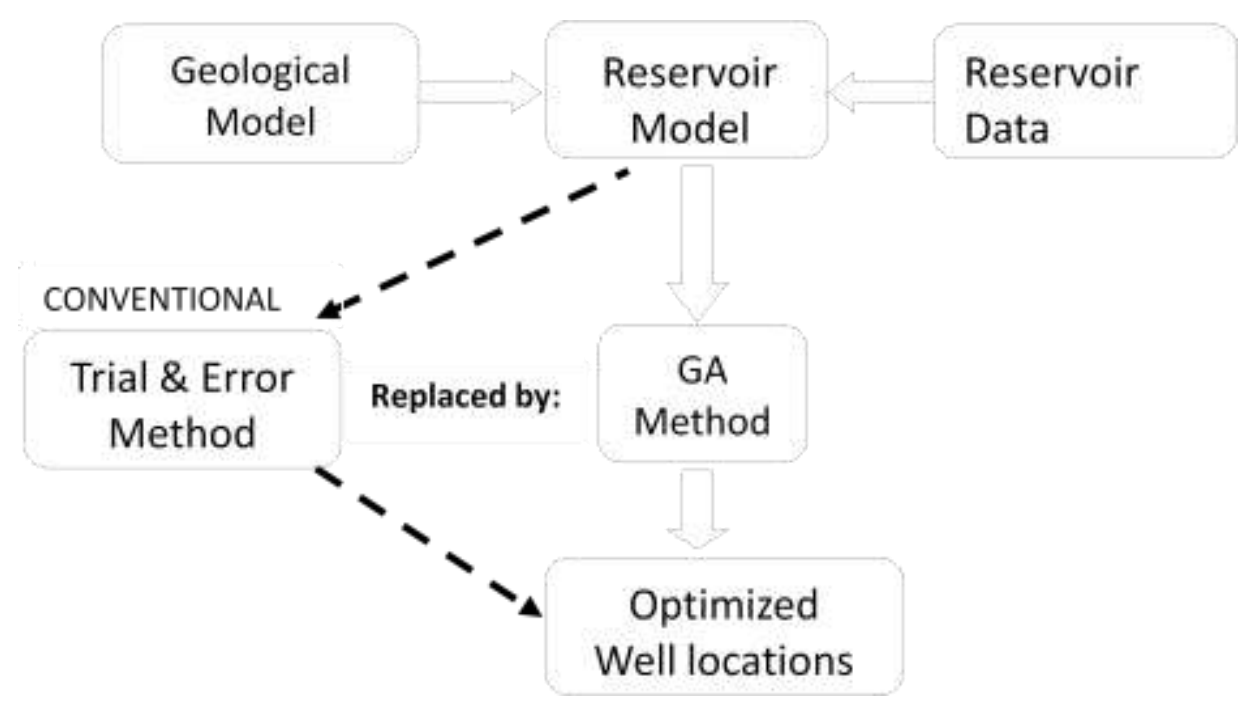

Figure 1 Research Methodology of This Study: Replacing the Conventional Trial \& Error Method by a Proposed Genetic Algorithm Method.

\section{$3 \quad$ Field Descriptions for Reservoir Modeling Input}

A reservoir simulation using a commercial finite difference reservoir simulator requires a set of reservoir data, geological model, reservoir fluid properties, rock properties model, and driving mechanism.

Two fields, namely $\mathrm{X}$ and $\mathrm{Y}$, were used to evaluate the GA application performance. The $\mathrm{X}$ field is discussed more in details than the $\mathrm{Y}$ field since the $\mathrm{X}$ field was used to evaluate the proposed objective functions and performance of the GA, whereas, the Y field was used for further validation of the proposed GA for a different condition of reservoir.

The $\mathrm{X}$ and $\mathrm{Y}$ fields had a similar geological depositional environment. However, the $\mathrm{X}$ Field was relatively small and was still in its early 
development, and, the Y field was relatively larger and was a mature field. Thus, the fields' profile characteristics that differentiate these two fields are that the latter is in the stage of declining production, and in addition, it has poorer reservoir rock characteristics and does not have many faults as the previous field does. Thus, the oil saturation profiles between those fields should be in big different profile characteristics. Figure 2 shows the $Y$ field in three dimensional map, constructed using reference 10, of top depth structure that consists of several small anticlines indicating a big field with many production wells. This depth structure map is an input in the reservoir simulator using reference [10] and the reservoir is divided into grid blocks.

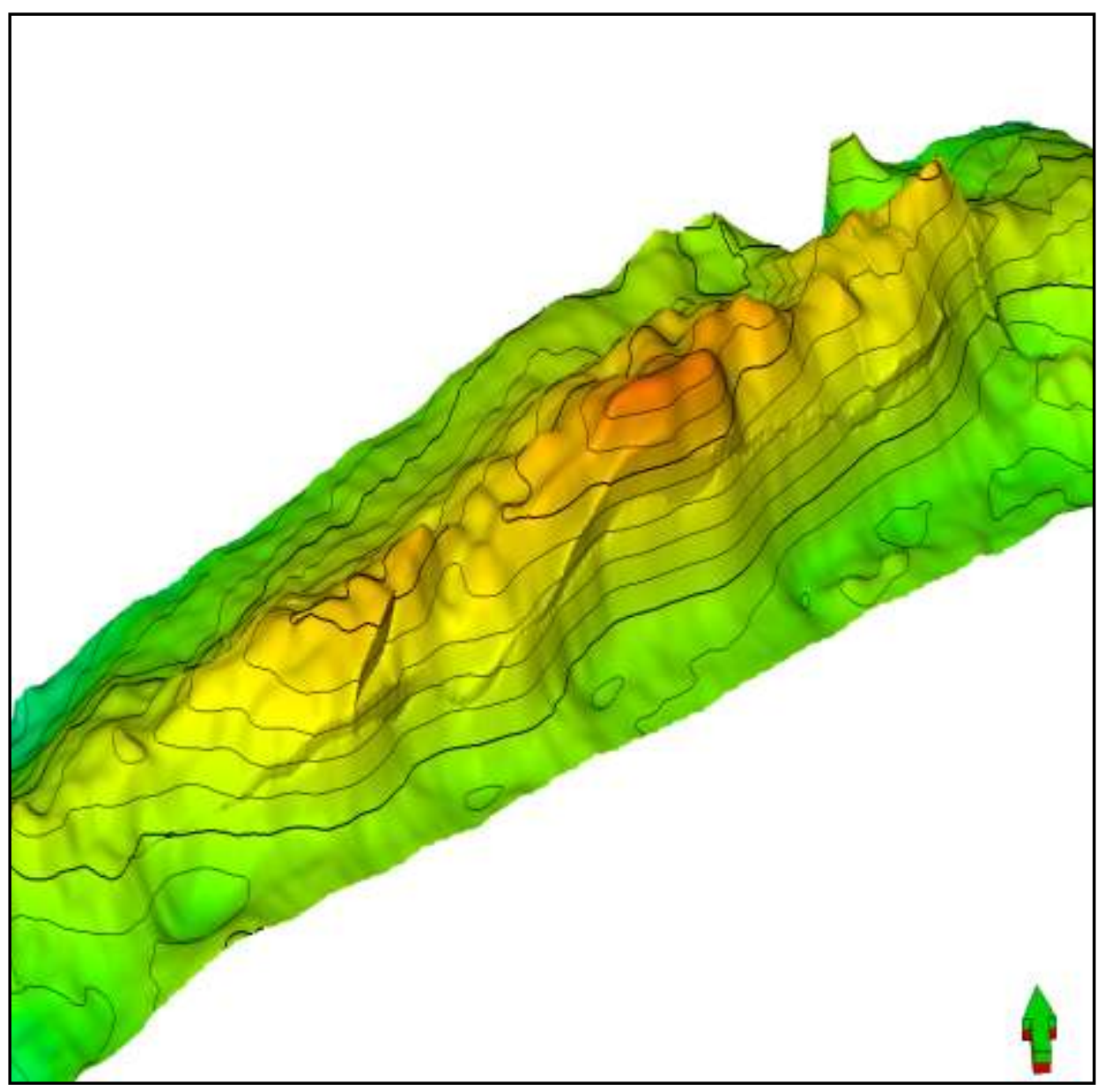

Figure 2 The Y Field Three Dimensional Map of Top Depth Structure. 


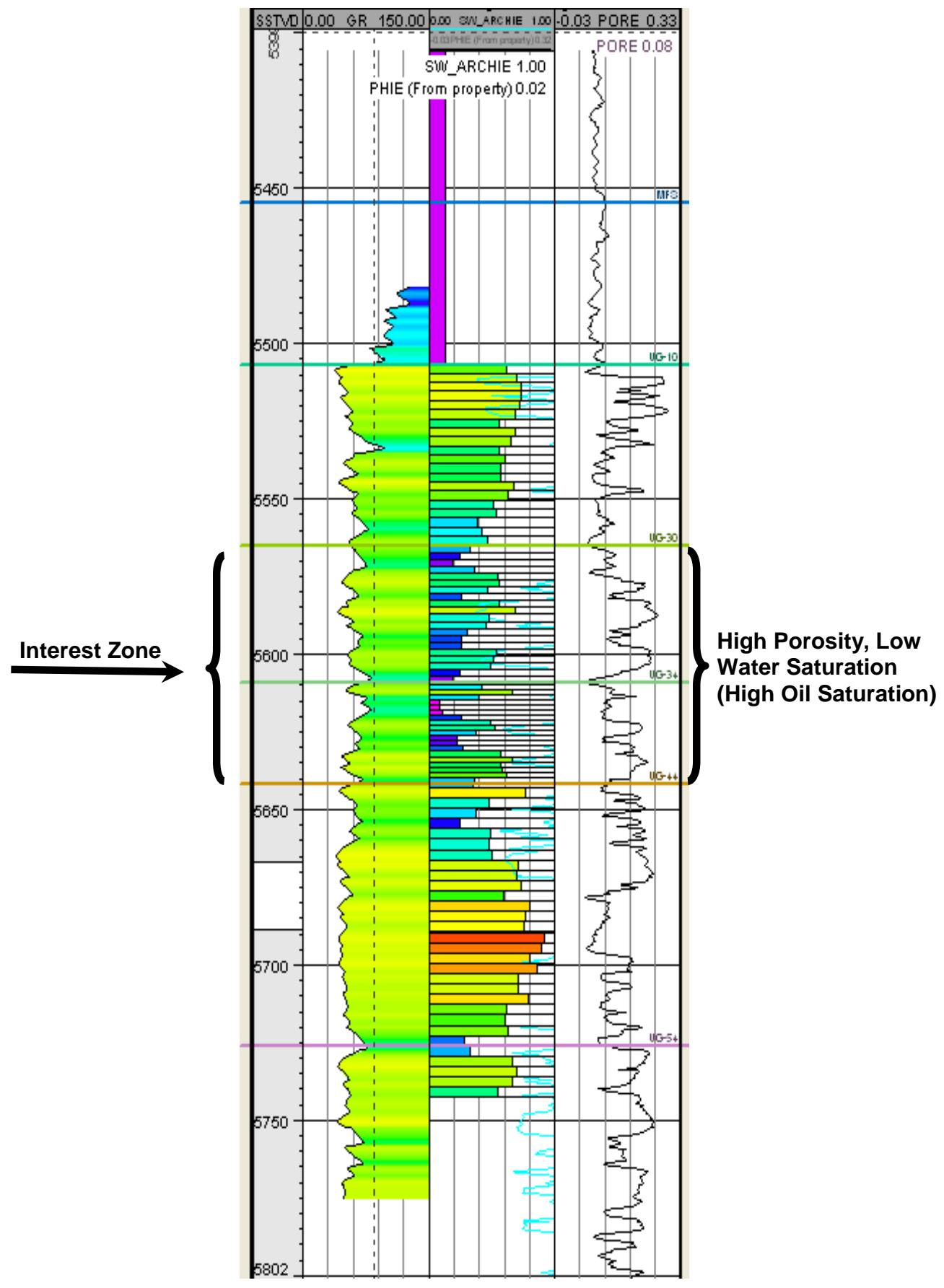

Figure 3 Typical Well Logs of the X Fields. 
Besides, petrophysical properties that were obtained from well log and reservoir core sample analyses were also required for the development of the reservoir model. For example, the X-field consisted of six zones of the reservoir, namely (from top to bottom) L-1, L-2, L-3, L-4, L-5 and L-6 as depicted by Figure 3. This figure is a typical well log indicating that the L3 zone had a better quality due to the higher porosities and oil saturations (low water saturations).

\subsection{Fluid Properties of Field X}

The initial reservoir pressure was 2440 psi with the bubble point pressure ranging from 1901 to 2097 psi. The oil gravity in this field was $32^{\circ}$ API with viscosity $0.94 \mathrm{cp}$, and Formation Volume Factor (FVF) of oil $1.325 \mathrm{Bbl} / \mathrm{STB}$. It can be concluded that the reservoir fluid was a black oil reservoir fluid type. In this Block, there were two exploration wells which were X-2 and X-7. From the test on X-2 well it was found that in the initial reservoir condition, significant oil production was discovered from several layers (L-1, L-2, L-3, and L-4).

\subsection{Property Model of X Field}

Sequential Gaussian Simulation (SGS) distribution method was used to distribute the reservoir properties, i.e., porosity, permeability, and water saturation (or oil saturation) for all grids. The average porosity and permeability of the field were $12 \%$ and $147 \mathrm{mD}$, and Figure 4, 5, 6 are results of using simulator [11] that described porosity, water saturation, and permeability distributions, respectively.

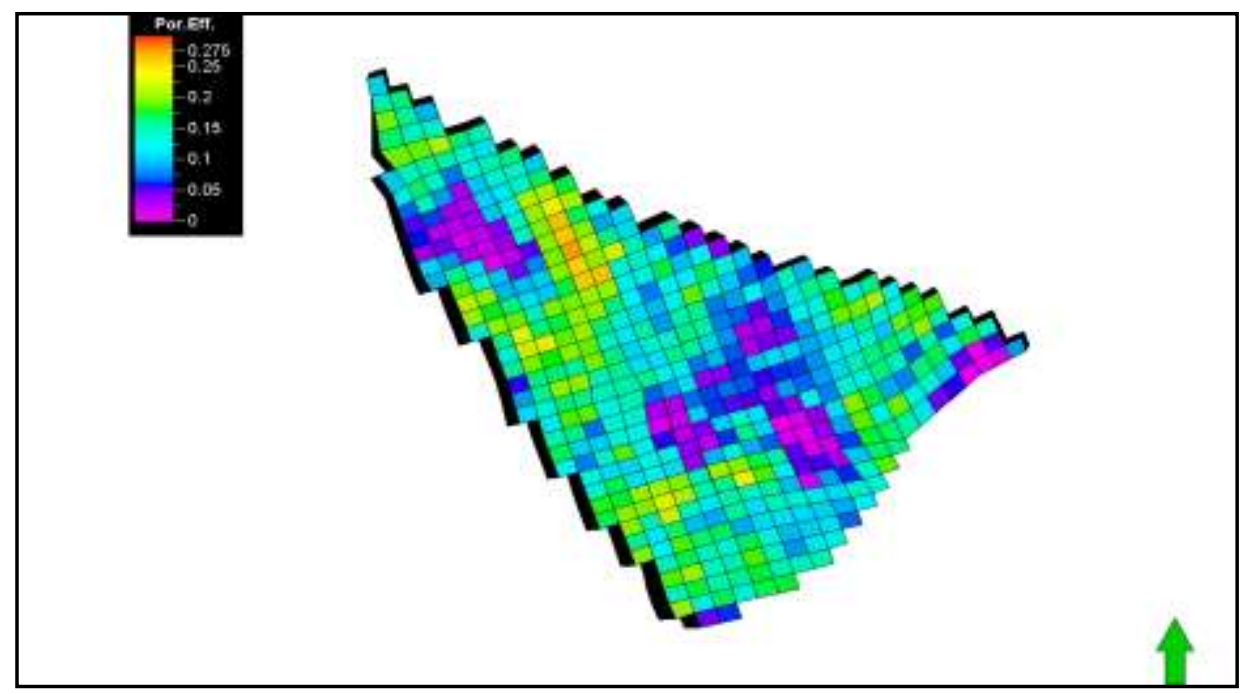

Figure 4 Porosity Distribution of the Interest Zone in the X Field. 


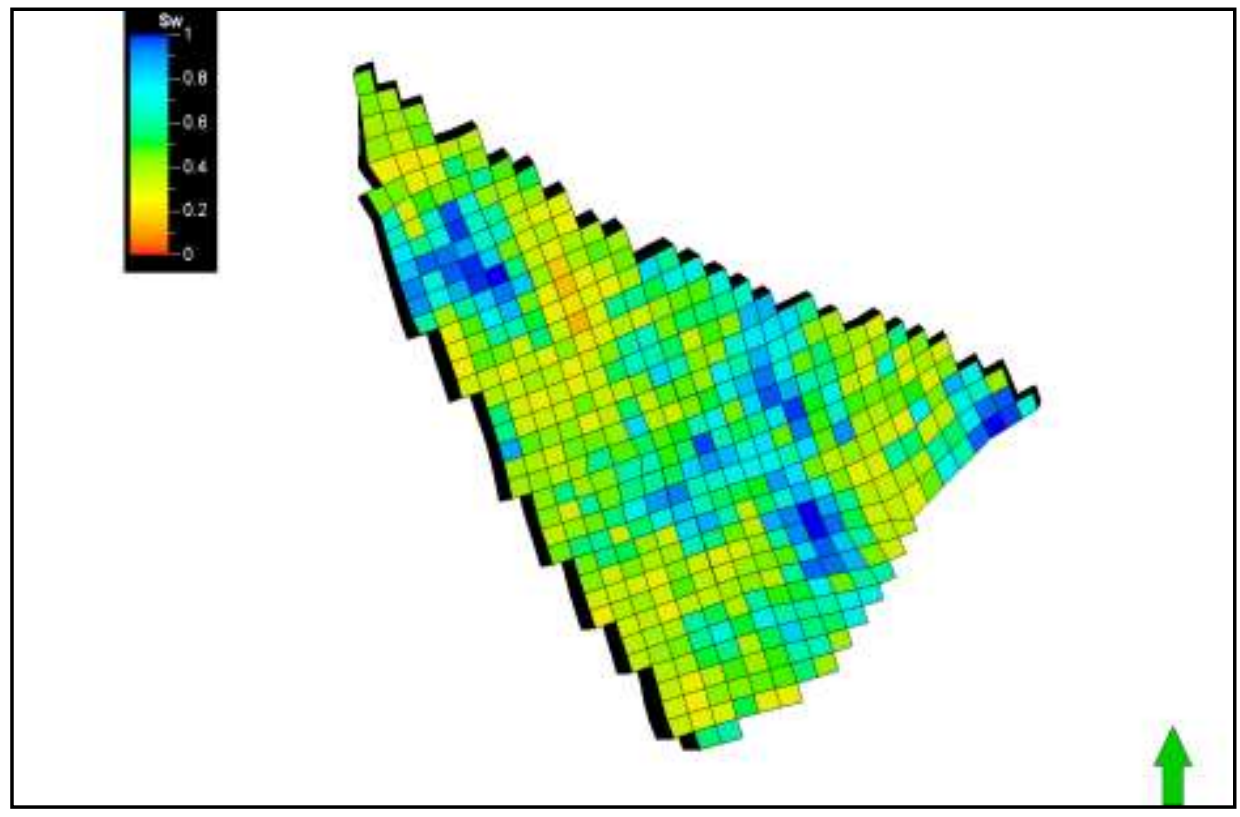

Figure 5 Water Saturation Distribution of the Interest Zone in the X Field.

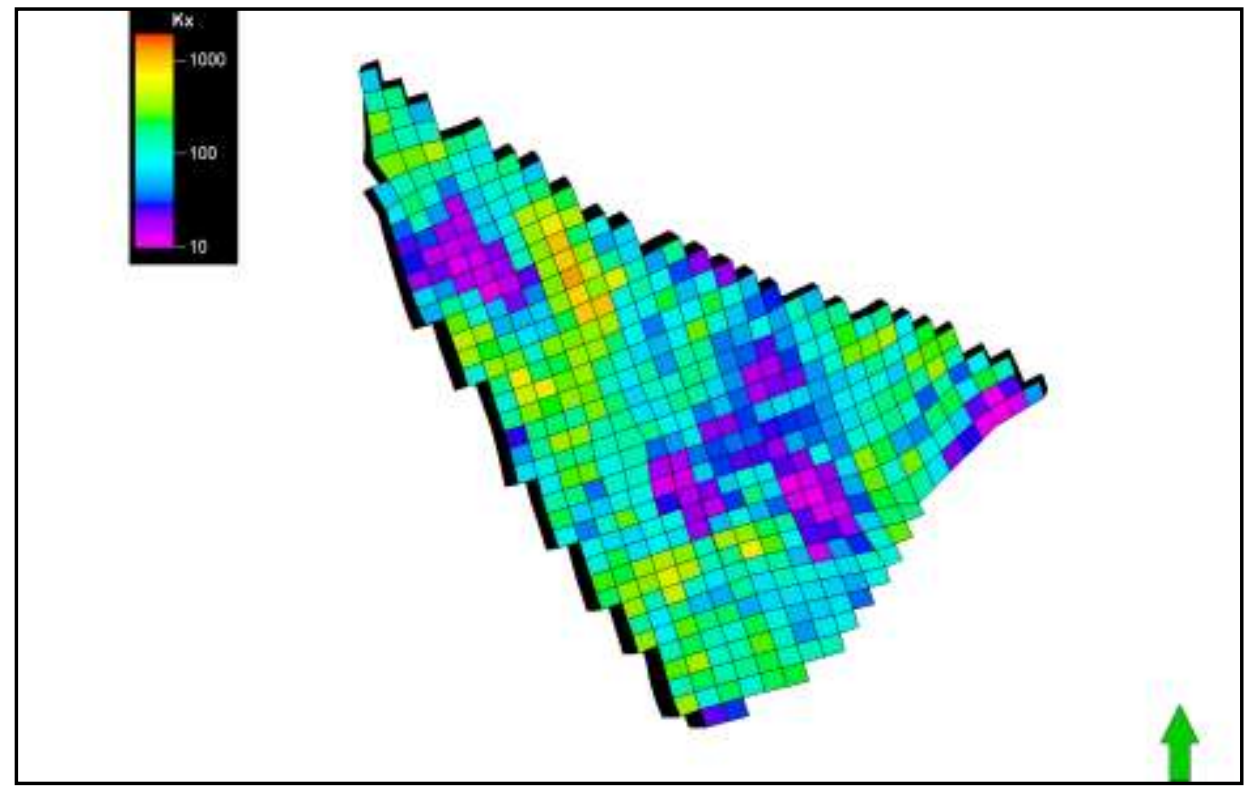

Figure 6 Permeability Distribution of the Interest Zone in the X Field. 


\section{Reservoir Simulation Model of the X Field}

This study focuses on L-2 that contained the highest hydrocarbon, and therefore other layers are deliberately not included in this study. In this model the type of corner point grid was applied and the type of the simulator was a black oil reservoir fluid. The reservoir model of this field was up scaled into $28 \times 39 \times 1$ simulation grids and the number of active cells was 1092 .

\section{Reservoir Simulation Model of the Y Field}

To further validate this study, another field was examined by this proposed method to find the best infill well location. A reservoir model of this Y-field was available, which had more than 25 development wells. The main goal of this application was to further validate this well location selection method with different profiles of field, especially, the production performance of this mature field with many number of wells. However, the reservoir description of the $\mathrm{Y}$ field is not described in details in this paper. Figures 7, 8, and 9 show the Y field maps of porosity, water saturation, and permeability distribution. The figure shows that there was only a small area of potential oil remaining reserve left, and this created a challenge for the method to be able to find that area.

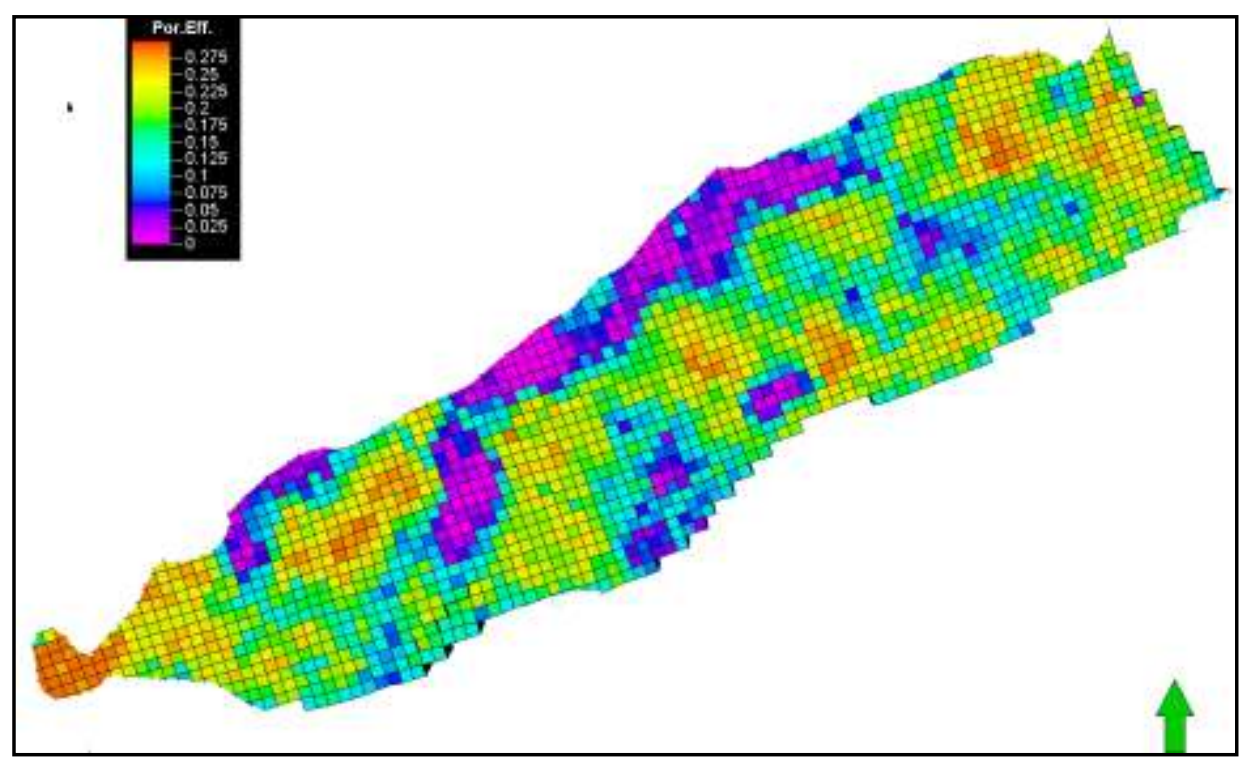

Figure 7 Porosity Distribution of the Interest Zone in the Y Field. 


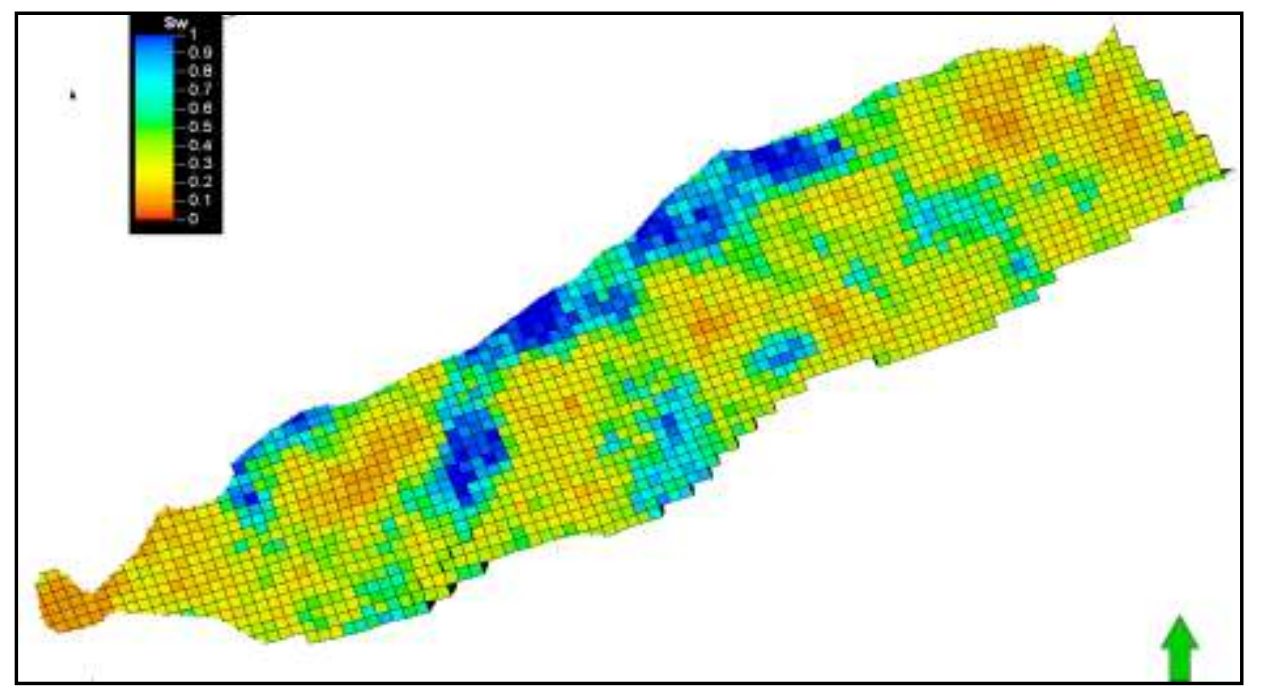

Figure 8 Water Saturation Distribution of the Interest Zone in the Y Field.

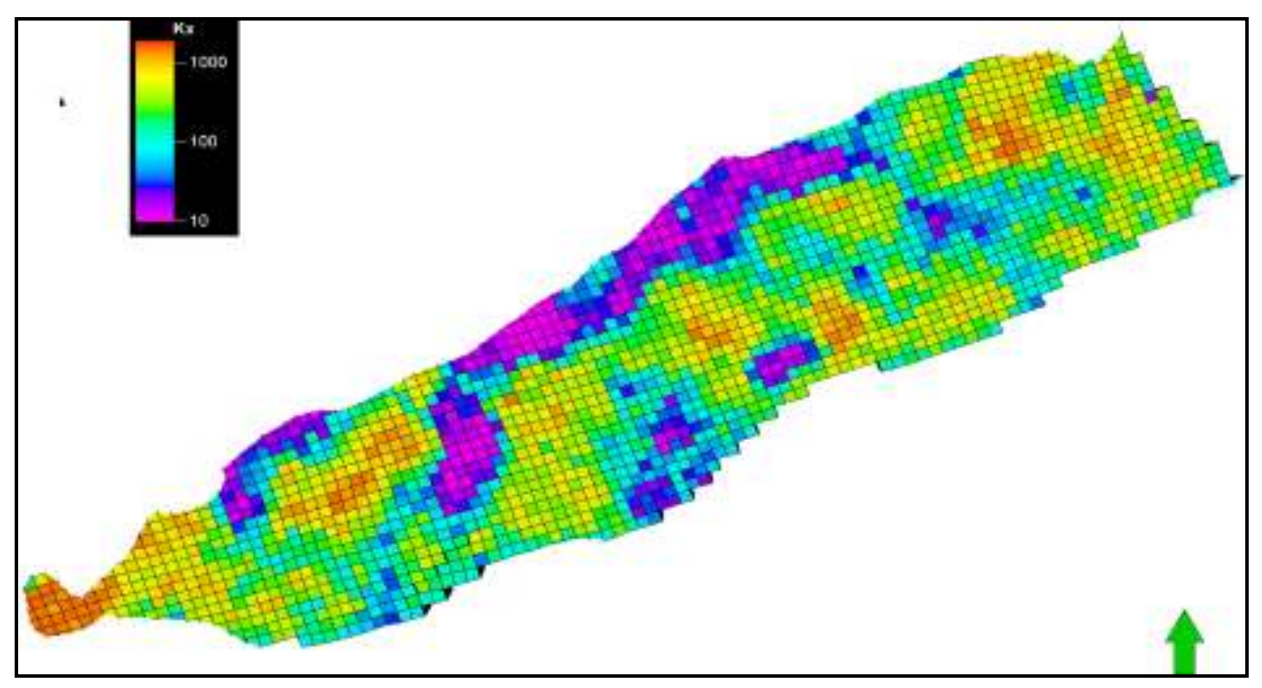

Figure 9 Permeability Distribution of the Interest Zone in the Y Field.

\section{Genetic Algorithm Process and Application}

GA that was initially developed by Holland [1] in 1968 is a computer based with random search technique that is inspired by Darwinian Theory of natural evolution process [2]. The main idea of GA is to find out a solution from genetics of probable solutions. 
GA can be implemented in different disciplines of knowledge such as in business, engineering and science. GA is quite robust, resulting solution near optimum and not easily trapped in local optimum [7]. Another advantage of this method is that the algorithm is flexible and does not require such stringent requirements of differential mathematics, continuity and others. Therefore, this algorithm method is recommended to be developed to overcome problems that are too complex and too difficult to be solved by the conventional techniques.

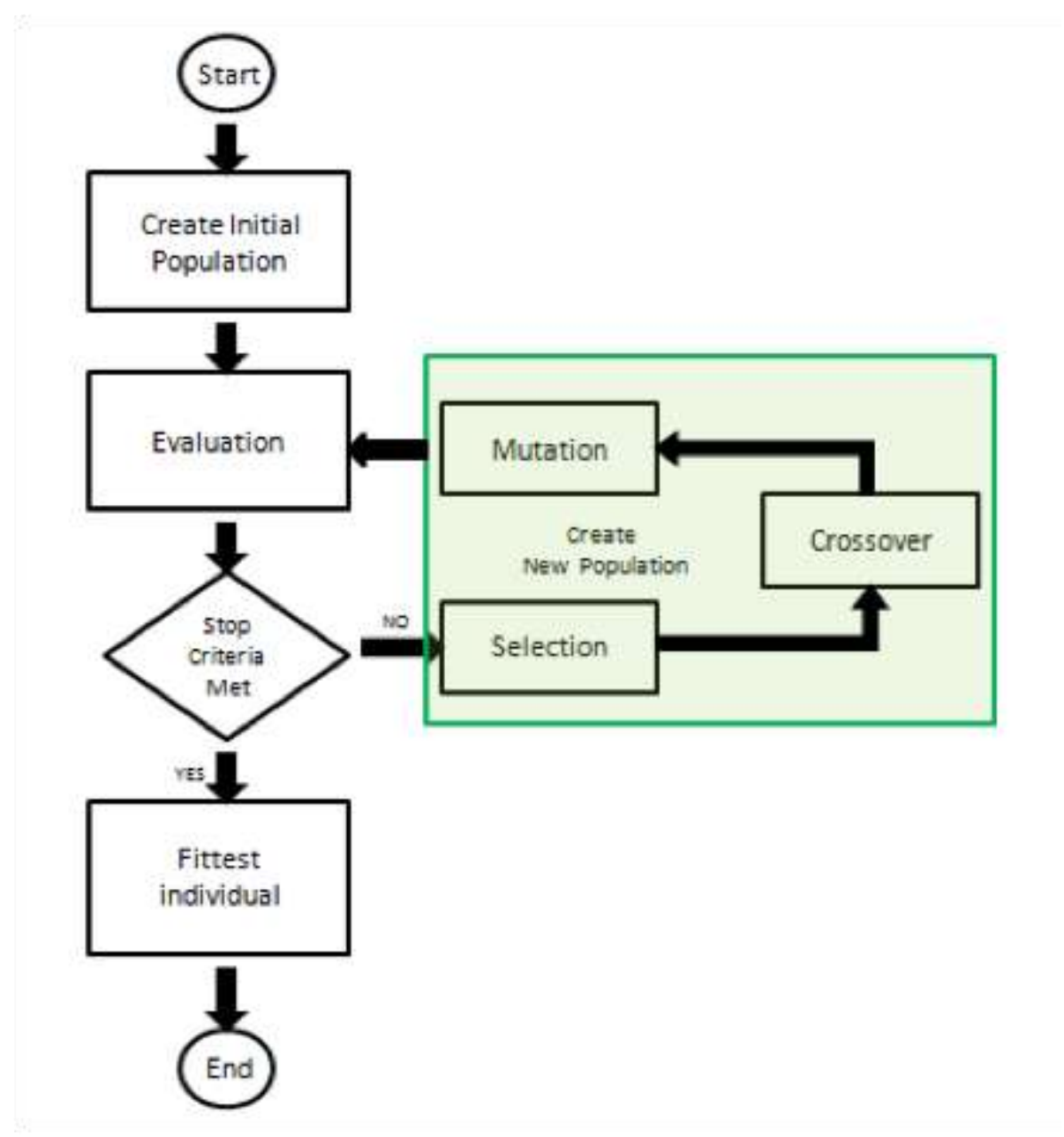

Figure 10 Flowchart of the Genetic Algorithm. 
The following are the characteristics of genetic algorithm [1-2]:

GA works with coding of the parameters, but it does not directly manipulate the parameters.

GA searches not only one point as a solution to the problems, but also investigates several numbers of points as a candidate solution.

In running GA, the existence of an objective function to solve the problem is required.

The realization of GA uses the probabilistic rules.

In simple terms, a flow chart of the genetic algorithm process is illustrated in Figure 10.

Following the above flowchart, in this research, the genetic algorithm model is as follows:

Representation of the population. It is known that the desired solution is the location represented by $(x, y)$ coordinates.

The length of the binary of population is determined by bit_var parameter given by user.

The Operator of selection, crossover and mutation. These operators are conducted to get a new population representing the new well location. In this research, the model used the basic rule of selection, crossover and mutation.

The determination of fitness function that represents an objective function.

To explain briefly a GA model, the following example give an illustration. The first step is to determine values of crossover probability, mutation probability and population size, i.e., $0.85,0.01$ and 10 , respectively. Then, an initial population is generated using random binary numbers as depicted in Figure 11 (a) that shows an initial population of well locations in a binary representation of $\mathrm{X}$ and $\mathrm{Y}$ coordinates. This initial population is then evaluated by calculating values of a developed fitness function. A maximum value of the fitness function value is an optimum solution. In order to find this optimum solution, evolution operators that are selection, crossover and mutation are applied to obtain better quality of a new population. Figure 11 (b) and (c) show the illustrative examples of crossover and mutation process. 


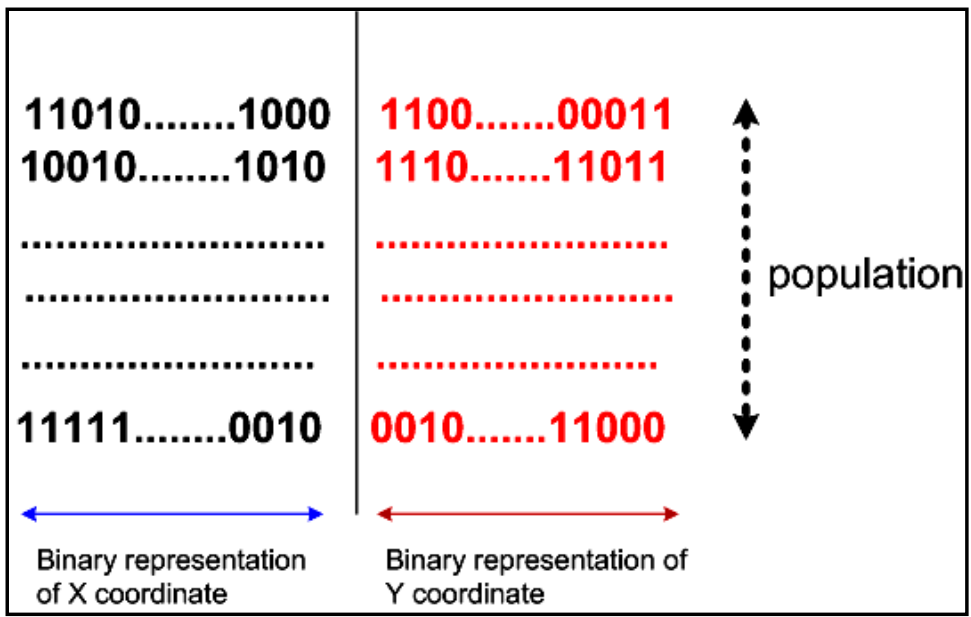

(a)

\begin{tabular}{|c|c|c|}
\hline $\begin{array}{l}\text { Parent 1 } \\
\text { Parent 2 }\end{array}$ & $\begin{array}{l}10000100111 \\
011 \\
0\end{array}$ & Old string $\quad 11000101110$ \\
\hline $\begin{array}{l}\text { New string } 1 \\
\text { New string } 2\end{array}$ & $\begin{array}{l}1000 \\
1001100001 \\
0110 \\
0100111\end{array}$ & New string 11001101110 \\
\hline
\end{tabular}

(b)

(c)

Figure 11 (a) Binary Representation for well location. (b) Illustration of crossover. (c) Illustration of mutation.

\section{$7 \quad$ Objective Function Development}

The location of the development and/or infill wells in the oil reservoir model is selected based on the values of oil saturation/water saturation, permeability and porosity of rock at the certain grid block, oil and water viscosity, and the distribution of rock properties and saturation in the adjoining grid blocks. Porosity and oil saturation represents the amount of hydrocarbon in the reservoir, while permeability represents the ability of fluid to flow through porous media. The selected grid block, where the well will be located, should have a good flow potential which is supported by those parameters in the adjoining grid blocks in $\mathrm{i}, \mathrm{j}, \mathrm{k}$ directions. These parameters represent the well productivity and therefore the selected grid block where the well will be located will have good productivity. Since the well productivity depends on the value of those parameters in the adjoining grid blocks, it will form the drainage area of the well; thus, if the values of those parameters in the adjoining grid blocks are maximum, they will produce high well productivity. In this research, these parameter values are presented as a function that consists of the amount of oil in the grid blocks (porosity, oil saturation, and grid block thickness), oil mobility 
(permeability and viscosity of oil), and pressure gradient. The single representation of each grid block basically shows the value of the productivity if the dynamic parameter that is differential pressure is included. However, this study was based on the static quantitative representation of each grid block. In this research, it is called fitness function. Based on this definition, the grid block to be selected as the location of well should have the maximum value of fitness function. The fitness value indicates whether an individual from a population has a good quality or not. For practicality, the individual in this study was a reservoir simulation grid that contained three most important basic reservoir properties, which were porosity, oil saturation, and permeability, used as variables in the objective function. As a logical consequence, the amount of hydrocarbon had a higher level of priority than the permeability in the selection process.

As a consequence, two sequential objective functions were proposed to execute the GA for this study method. The first one was to classify candidate grids based on their porosity and saturation, represented as:

Classification of grids $=\left\{\begin{array}{c}D_{A}=\{(x, y) \in D: f(g(x, y), h(x, y)) \in[0.4,1]\} \\ D_{B}=\{(x, y) \in D: f(g(x, y), h(x, y)) \in[0.2,0.4]\} \\ D_{C}=\{(x, y) \in D: f(g(x, y), h(x, y)) \in[0.1,0.2]\} \\ D_{D}=\{(x, y) \in D: f(g(x, y), h(x, y)) \in[0,0.1]\}\end{array}\right\}$

with

$$
f(g(x, y), h(x, y))=g(x, y) * h(x, y)
$$

where $D$ was a domain representing the reservoir grid, $f$ was the function of combination value between porosity and saturation on the certain grid, $g(x, y)$ was the value of porosity on $x, y$ coordinates, and $h(x, y)$ was the value of saturation on $x, y$ coordinates.

The next step was based on the evaluation of drainage radius. A reservoir system involved a dynamic process of fluid flow from reservoir to well bore, thus, surrounding grids of a well contribute to the well production. In the GA computer programming using the above mentioned objective functions, the problem was to quantify fluid flows of the surrounding well grids to the well production. However, it was obvious that the closer a grid to a well was, the bigger it contributed to the well production. The assumed drainage area where the properties of grids surrounding production well was taken into consideration in the objective function calculation called radius of evaluation, R. The formulation of the objective function is as follow: 


$$
\max _{(x, y) \in R} F(g(x, y), h(x, y), i(x, y))=\overline{g(x, y)} * \overline{h(x, y)} * \overline{i(x, y)}
$$

where $\overline{g(x, y)}$ is average of porosity value on $x, y$ coordinate, $\overline{h(x, y)}$ is average of saturation value on $x, y$ coordinate, $\overline{i(x, y)}$ is average of permeability value on $x, y$ coordinate.

In this research, the alternative wells location could be also resulted by sorting of the best individual based on fitness values and by considering the euclidean distance of each other.

It has been mentioned that in the GA application, the radius of the evaluation should be determined and evaluated. For the $\mathrm{X}$ field, it was proved that when $\mathrm{R}$ was 0 , it gave the best solution. Having the same procedures as the $\mathrm{X}$ field, it was found that at $\mathrm{R}$ equaled to 1 , it gave the best solution for the $\mathrm{Y}$ field.

\section{$8 \quad$ Results and Discussion}

To evaluate the performance of the proposed GA, the results were compared with the manual conventional well location selection results. There were two scenarios investigated, i.e., one and three well scenarios. All scenarios were set with the same constraints as on objective function evaluation, and all wells were opened simultaneously.

\subsection{The Manual Conventional Trial and Error Reservoir Simulation Results}

In the manual conventional reservoir simulation, a trial and error process of selecting the best grid locations was conducted by iteratively considering the three basic reservoir properties, i.e., of porosity, oil saturation, and permeability, and running the reservoir simulation by a one-by-one application at the chosen locations. Logically, the best location is where the highest values of the those three properties are at the same place, although this is almost impossible or unrealistic, especially for a large field. However, for this considerably fair size of field, the resulted best grids locations could be ranked. Here, we also presented results of the multi well scenarios where a drainage radius was considered, and for the rule of thumb, it was assumed to be 2 grids neighborhood. The radius of the evaluation equaled to zero $(\mathrm{R}=0)$, which means that the drainage radius was only the well grid; $R=1$ means that there was one surrounding neighbor grid of the well grid, and $\mathrm{R}=2$ means that there were two surrounding neighbor grids. 
Table 1 and 2 describe well the locations and oil recoveries of $\mathrm{X}$ field resulted from the conventional trial and error, compared to the previous results of the reservoir simulation, of One Well Scenario and Three Well Scenario cases, respectively. The radius of the evaluation equals to zero $(\mathrm{R}=0)$ which means that the well drainage radius was only the well grid. And so, $\mathrm{R}=1$ and $\mathrm{R}=2$ mean that the well drainage radius were 1 surrounding grid and 2 surrounding grids from the well grid.

Table 1 The One Well scenario Case of the $\mathrm{X}$ field for $\mathrm{R}=0$.

\begin{tabular}{|c|c|c|c|c|}
\hline \multicolumn{2}{|c|}{ Location } & \multirow{2}{*}{$\begin{array}{l}\text { Oil Recovery } \\
\text { (STB) }\end{array}$} & \multirow{2}{*}{$\begin{array}{c}\text { Recovery Factor } \\
(\%)\end{array}$} & \multirow{2}{*}{$\begin{array}{c}\Delta \text { RF with Res. Simulation } \\
(\%)\end{array}$} \\
\hline $\mathrm{X}$ & $\mathrm{Y}$ & & & \\
\hline 7 & 27 & 2891840.5 & 17.94 & 0 \\
\hline
\end{tabular}

Table 2 The Three Wells scenario Case of the $\mathrm{X}$ field for $\mathrm{R}=0$.

\begin{tabular}{|c|c|c|c|c|}
\hline \multicolumn{2}{|c|}{ Location } & \multirow{2}{*}{$\begin{array}{l}\text { Oil Recovery } \\
\text { (STB) }\end{array}$} & \multirow{2}{*}{$\begin{array}{c}\text { Recovery Factor } \\
(\%)\end{array}$} & \multirow{2}{*}{$\begin{array}{c}\Delta \text { RF with Res. Simulation } \\
(\%)\end{array}$} \\
\hline $\mathrm{X}$ & $Y$ & & & \\
\hline 7 & 27 & 3521585 & 21.85 & 0.15 \\
\hline 18 & 24 & & & \\
\hline 9 & 27 & & & \\
\hline
\end{tabular}

$\Delta$ RF with Res. Simulation: differences with respect to the previous Reservoir Simulation results.

Moreover, Table 3 and 4 describe well the locations and oil recoveries of the Y field for One Well Scenario and Three Well Scenarios, respectively.

Table 3 The One Well scenario Case of the Y field for $\mathrm{R}=0$.

\begin{tabular}{|c|c|c|c|c|}
\hline \multicolumn{2}{|c|}{ Location } & \multirow{2}{*}{$\begin{array}{c}\text { Oil Recovery } \\
\text { (STB) }\end{array}$} & \multirow{2}{*}{$\begin{array}{c}\text { Recovery Factor } \\
(\%)\end{array}$} & \multirow{2}{*}{$\begin{array}{c}\Delta \text { RF with Res. Simulation } \\
(\%)\end{array}$} \\
\hline $\mathrm{X}$ & $\mathrm{Y}$ & & & \\
\hline 90 & 36 & 9825374 & 8.98 & 0.41 \\
\hline
\end{tabular}

Table 4 The Three Wells scenario Case of the $\mathrm{Y}$ field for $\mathrm{R}=0$.

\begin{tabular}{ccccc}
\hline \multicolumn{2}{c}{ Location } & $\begin{array}{c}\text { Oil Recovery } \\
\text { X }\end{array}$ & $\begin{array}{c}\text { Recovery Factor } \\
(\%)\end{array}$ & $\begin{array}{c}\Delta \text { RF with Res. Simulation } \\
(\%)\end{array}$ \\
\hline 90 & 36 & 16448811 & 14.03 & 1.31 \\
105 & 34 & & & \\
79 & 36 & & & \\
\hline
\end{tabular}

We can see that the One Well Scenario Case still had perfect results as shown by much lower differences from the previous reservoir simulation results, for both of the fields. However, the bigger field possessed a bigger difference. Moreover, the Three Well Scenario Case yielded higher differences than that of the One Well Scenario case. This clearly shows that the more complex the 
problems were, i.e., bigger number of well and bigger field, the bigger the differences were. Thus, this conventional trial and error method is likely to be hard and time consuming to find an accurately best well location as the field size gets bigger.

\subsection{Objective Functions Evaluation of the Proposed GA Method}

The objective functions of the proposed GA method should be evaluated first in order to avoid local optimum solutions. Also, in order to have a proper radius of evaluation, the GA application is run for various radii of evaluation.

Some statistical parameters should be properly assumed to run the GA application for this study optimization problem. Table 5 shows the suitable GA parameters for this case study. The population size means a number of grids that had specific properties of porosity, permeability, and water saturation in each grid. The maximum number of iteration was set to guarantee such a high value that a maximum value of the objective function could be achieved. Crossover probability was set to be 0.9 to give a high chance for the process of crossover to happen. But, it was not equal to always happening or to $100 \%$. On the other hand, the mutation probability equal to 0.01 is meant to a limit a mutation that occurred, and thus, a new individual is generated mostly through combination of individuals.

Table 5 GA Calculation Parameters for the proposed GA method

\begin{tabular}{|ll|}
\hline Population size & 100 \\
Maximum Number of iteration & 1500 \\
Crossover Probability & 0.9 \\
Mutation Probability & 0.01 \\
Number of variables & 2 (x and y) \\
Chromosome Length & 20 for each variable \\
Interval & {$[1-28]$ for $x$ and $[1-39]$ for $y$} \\
Radius of evaluation & $0,1,2,3,4$ \\
\hline
\end{tabular}

To check the application, the results from some iteration were investigated by evaluating the proposed well locations obtained from the reservoir simulation runs. For all the simulation runs, the producing well time schedule was set for 15 years with oil rate target of 2000 STB/Day. Table 6 describes the results of the application for $\mathrm{R}=0$ in some iteration, and, Figure 12 and 13 illustrate the relationships between the number of iteration, fitness value, and oil recovery. 
As can be seen, the proposed well location that moved from iteration to iteration indicated that the proposed GA method searched for the best location. And, the fitness values always became bigger during the iteration of the calculation (Fig. 12 ) as well as the recovery factor (Figure 13). This also means that the proposed GA method will not be trapped into a local minimum.

Table 6 The proposed GA and Reservoir Simulation Results for $R=0$.

\begin{tabular}{|c|c|c|c|c|c|c|c|}
\hline \multirow{2}{*}{ Iteration } & \multicolumn{2}{|c|}{ Location } & \multirow{2}{*}{$\begin{array}{l}\text { Fitness } \\
\text { Values }\end{array}$} & \multirow{2}{*}{ Porosity } & \multirow{2}{*}{$\begin{array}{c}\text { Oil } \\
\text { Saturation }\end{array}$} & \multirow{2}{*}{$\begin{array}{c}\text { Permeability } \\
\text { (mD) }\end{array}$} & \multirow{2}{*}{$\begin{array}{l}\text { Oil Recovery } \\
\text { (STB) }\end{array}$} \\
\hline & $\mathrm{x}$ & $\mathrm{y}$ & & & & & \\
\hline 1 & 5 & 27 & 30.096 & 0.27 & 0.817 & 270.3 & 2089725.3 \\
\hline 5 & 5 & 27 & 30.096 & 0.27 & 0.817 & 270.3 & 2089725.3 \\
\hline 10 & 5 & 27 & 30.096 & 0.27 & 0.817 & 270.3 & 2089725.3 \\
\hline 100 & 7 & 28 & 30.219 & 0.32 & 0.818 & 516.1 & 2777452.3 \\
\hline 500 & 7 & 28 & 30.219 & 0.32 & 0.818 & 516.1 & 2777452.3 \\
\hline 900 & 7 & 28 & 30.219 & 0.32 & 0.818 & 516.1 & 2777452.3 \\
\hline 1000 & 7 & 27 & 30.274 & 0.34 & 0.818 & 614.8 & 2891840.5 \\
\hline 1500 & 7 & 27 & 30.274 & 0.34 & 0.818 & 614.8 & 2891840.5 \\
\hline
\end{tabular}

Furthermore, these analyses were also implemented for $\mathrm{R}=1,2,3$, and 4, and the results are summarized in Table 7 . These results show that the proposed GA method was not trapped in a local optimum, except for the radius of evaluation equal to 1 . And, the radius of evaluation equal to 0 is the best radius of the evaluation parameters for the $\mathrm{X}$ field, because its location result gave the highest oil recovery.

Table 7 Results from various $R$.

\begin{tabular}{|c|c|c|c|c|}
\hline \multirow{2}{*}{ Radius } & \multicolumn{2}{|c|}{ Location } & \multirow{2}{*}{$\begin{array}{l}\text { Fitness Value - Oil } \\
\text { Recovery Relation }\end{array}$} & \multirow{2}{*}{ Oil Recovery (STB } \\
\hline & $x$ & $Y$ & & \\
\hline 0 & 7 & 27 & Positive & 2891840.5 \\
\hline 1 & 6 & 27 & Negative & 2310701.8 \\
\hline 2 & 8 & 27 & Positive & 2418505.0 \\
\hline 3 & 8 & 27 & Positive & 2418505.0 \\
\hline 4 & 9 & 28 & Positive & 1881947.1 \\
\hline
\end{tabular}




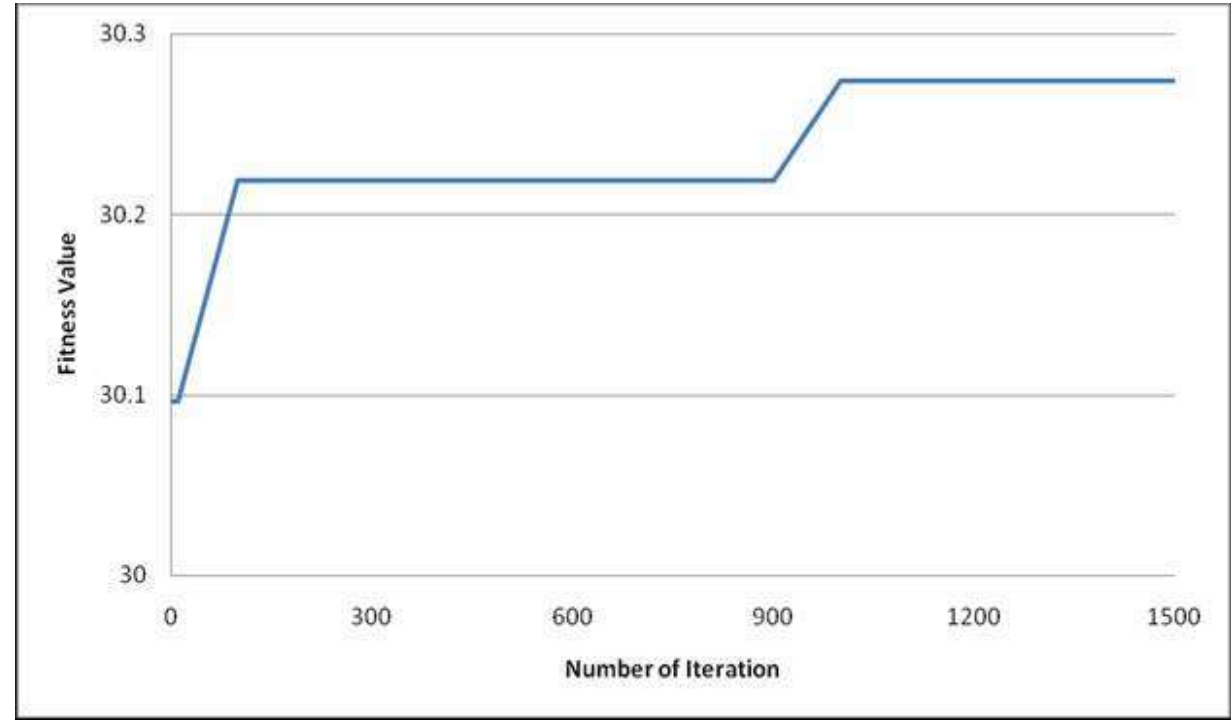

Figure 12 Fitness Value Evaluation with respect to Number of Iteration.

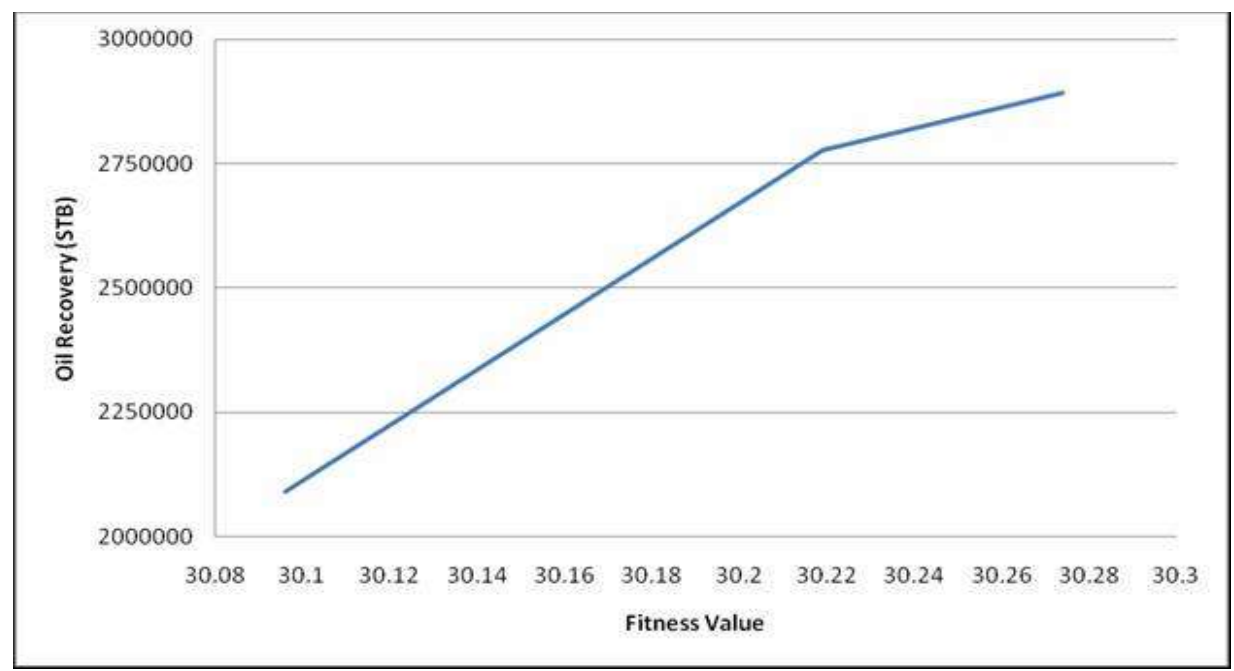

Figure 13 Oil Recovery Evaluation with respect to Fitness Function. 


\subsection{The Proposed GA Method Results}

Results of the proposed GA method for both fields are described in Table 8 11. A similar phenomena that the One Well Scenario Case still has perfect results as shown by small differences compared to the reservoir simulation results for both fields. However, for the bigger field posses a bigger difference. Also, the Three Well Scenario Case yielded higher differences than the One Well Scenario case. In other words, using the robust and accurate proposed GA method might solve hurdles in the more complex problems, i.e., bigger number of well and bigger field; if we use the conventional trial and error method, it requires hard work and plenty of time to accurately find best well locations.

Table 8 The One Well scenario Case of $\mathrm{X}$ field for $R=1$.

\begin{tabular}{ccccc}
\hline \multicolumn{2}{c}{ Location } & $\begin{array}{c}\text { Oil Recovery } \\
\text { (STB })\end{array}$ & $\begin{array}{c}\text { Recovery Factor } \\
(\%)\end{array}$ & $\begin{array}{c}\Delta \text { RF with Res. Simulation } \\
(\%)\end{array}$ \\
\hline 7 & 27 & 2891840.5 & 17.94 & 0 \\
\hline
\end{tabular}

Table 9 The Three Wells scenario Case of X field for $R=1$.

\begin{tabular}{|c|c|c|c|c|}
\hline \multicolumn{2}{|c|}{ Location } & \multirow{2}{*}{$\begin{array}{l}\text { Oil Recovery } \\
\text { (STB) }\end{array}$} & \multirow{2}{*}{$\begin{array}{c}\text { Recovery Factor } \\
(\%)\end{array}$} & \multirow{2}{*}{$\begin{array}{c}\Delta \text { RF with Res. Simulation } \\
(\%)\end{array}$} \\
\hline $\mathrm{x}$ & $y$ & & & \\
\hline 7 & 27 & 3545128.3 & 22 & $0.15 \%$ \\
\hline 18 & 25 & & & \\
\hline 15 & 30 & & & \\
\hline
\end{tabular}

Table 10 The One Well scenario Case of Y field for $R=1$.

\begin{tabular}{ccccc}
\hline \multicolumn{2}{c}{ Location } & $\begin{array}{c}\text { Oil Recovery } \\
\text { (STB) }\end{array}$ & $\begin{array}{c}\text { Recovery Factor } \\
(\%)\end{array}$ & $\begin{array}{c}\Delta \text { RF with Res. Simulation } \\
(\%)\end{array}$ \\
\hline 91 & 34 & 10275948 & 9.39 & 0.41 \\
\hline
\end{tabular}

Table 11 The Three Wells scenario Case of Y field for $R=1$.

\begin{tabular}{ccccc}
\hline \multicolumn{2}{c}{ Location } & Oil Recovery & $\begin{array}{c}\text { Recovery Factor } \\
(\%)\end{array}$ & $\begin{array}{c}\Delta \text { RF with Res. Simulation } \\
(\%)\end{array}$ \\
\cline { 1 - 2 } $\mathrm{x}$ & $\mathrm{y}$ & $(\mathrm{STB})$ & 15.34 & 1.31 \\
91 & 34 & 16790774 & & \\
90 & 36 & & & \\
79 & 36 & & & \\
\hline
\end{tabular}

Figures 14 shows the well locations of the previous study result and those of this proposed method. 

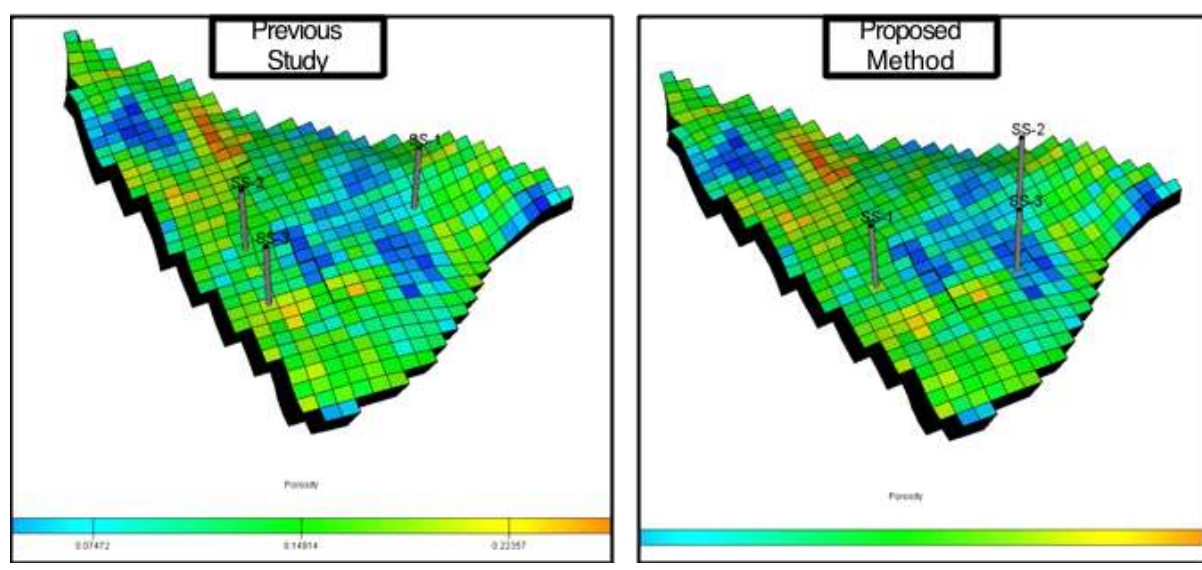

Figure 14 Well Locations of The Previous Study compared to those using GA Method.

\subsection{Discussion on the Proposed GA Method Calculation Procedure}

A two-step calculation procedure is introduced in this proposed method that employs two sequential objective functions. The first objective function is to classify the hydrocarbon volume and at some certain values are used for classification interval criteria. These assigned values are based on qualitative investigation on running experiments for the whole field using geological software. Thus, some subjective reservoir engineering judgments are embedded in this first objective function.

The proposed GA needed statistical parameters that had to be set properly in order to guarantee a genetic algorithm calculation process to work well. The maximum number of iteration in this program was set to be a certain number so that the calculation of the objective function reached the maximum value as the iteration proceeded; it did not produce significantly bigger values. The crossover probability was set to be a certain high value, i.e., 0.9, to enable the algorithm permissive to this process to happen. On the other hand, the mutation probability was set to be of small value, i.e., 0.1 , to limit the occurring mutation. This conditions were intended to yield more heterogeneous individuals since crossover allows a new individual generating from the combustion among individuals, whereas mutation allows a new individual generating from the individual itself.

The proposed GA method proved to be a robust way of finding the best well location as shown by its capability in resulting better oil production 
performance than the conventional reservoir simulation methods' for both studied fields, i.e., $\mathrm{X}$ and $\mathrm{Y}$ fields. For a simple problem of one well scenario of the $\mathrm{X}$ field, the proposed GA method gave the same result as the conventional method. For a three well scenario, the GA method could give at least the same or even better well location by producing a higher additional oil recovery of $0.15 \%$ over the conventional result. Furthermore, on the case of the Y field, for one and three wells development scenarios, the proposed method also could give better well locations by producing higher additional oil recoveries of $0.41 \%$ and $1.31 \%$, respectively, over the conventional method results.

The proposed GA involved the contribution of the surrounding grids in order to determine well locations. However, it needs further study to define the radius of evaluation since the radius of evaluation that determined the distance of the neighborhood grids still affected the well production set manually. The heterogeneity of the reservoir influenced the setting. Nevertheless, this simplification was powerful since the proposed GA was able to give good results for well locations selection.

\section{Conclusions}

The proposed GA method is proven to be a robust and accurate method to help find the best well locations for field development by employing three staticbasic reservoir rock parameters, i.e., porosity, permeability, and saturation, used in the conventional reservoir simulation practice. Thus, this method avoids the time consuming reservoir simulation process in searching the best field development scenario by running various forecasting future performance scenarios due to the use of the conventional, trial and error reservoir simulation method, especially for big size fields or condensate gas fields that need compositional simulators.

The key success of this proposed GA method mainly relies on the objective function formulation that requires experienced skills of in field development best practices using a reservoir simulation, and the ability to transform those skills into GA formulation in order to fulfill the objective or to solve the problems.

The inclusion of the radius of evaluation gave more realistic results of the proposed GA method in locating the best development well. However, this radius of evaluation needs to be studied further to find an automatic determination technique. 


\section{References}

[1] Dianati, M., Song, I. \& Treiber, M., an Introduction to Genetic Algorithms and Evolution Strategies, University of Waterloo, Ontario, N2L 3G1, Canada.

[2] Pham, D.T. \& Karaboga, D., Intelligent Optimization Techniques: Genetic Algorithms, Tabu Search, Simulated Annealing and Neural Networks, Springer, London, 2000.

[3] Rohani, N., Algoritma Genetika Dalam Optimasi Fungsi Dengan Kendala, ITB, Indonesia, 2003.

[4] Bittencourt, A.C. \& Horne, R.N., Reservoir Development and Design Optimization, SPE Annual Technical Conference and Exhibition. San Antonio, Texas, Paper SPE 38895, 1997.

[5] Ozdogan, U. \& Horne, R.N. Optimization of Well Placement with a History Matching Approach, SPE Annual Technical Conference and Exhibition. Houston, Texas, 2004.

[6] Montes, G., Bartolome, P. \& Angel,The Use of Genetic Algorithms in Well Placement Optimization, SPE Latin American and Caribbean Petroleum Engineering Conference, Buenos Aires, Argentina, 2001.

[7] Romero, C.E., Carter, J.N., Gringarten, A.C. \& Zimmerman, R.W., A Modified Genetic Algorithm for Reservoir Characterization, SPE International Oil and Gas Conference and Exhibition. Beijing, China, 2000.

[8] Romero, C.E., Carter, J.N., Gringarten, A.C. \& Zimmerman, R.w., Improve Reservoir Characterization through Evolutionary Computation, SPE Annual Technical Conference and Exhibition. Dallas, Texas, 2000.

[9] Dorington, K.P. \& Link, C.A., Genetic Algorithm/Neural Network Approach to Seismic Attribute Selection for Well-log Prediction, Geophysics, 69(1), 212-221, Society of Exploration Geophysicists, 2004.

[10] Petrel* Seismic to Simulation Software 2009 [Petrel 2009.1]. (2009). Houston: Schlumberger.

[11] Eclipse Simulation Software 2007 [Eclipse 2007.1] (2007). Houston: Schlumberger. 